\title{
Effects of the Teach-back Method of Self-care Education on the Pain Intensity and Sleep Quality of Rheumatoid Arthritis Patients
}

\author{
Seyedeh Robabeh Latifi Shahandashti', Zahra Kashaninia ${ }^{2}$, Alice khachian $^{3}$, Hamid Haghani ${ }^{4}$
}

\begin{abstract}
Background \& Aims: Rheumatoid arthritis is a chronic, inflammatory, and progressive autoimmune disease with variable clinical symptoms, which could also be the main cause of disability, short life, and even death. Pain is the most common symptom of rheumatoid arthritis, which plays a key role in the pattern of sleep and rest, and approximately $80 \%$ of patients with rheumatoid arthritis complain of sleep disorders. Among the other influential factors in the sleep pattern are inactivity and medication use. Sleep disturbance could increase pain, fatigue with depression, inflammation, and even disease and symptom deterioration. The patients mostly refer on an outpatient basis and receive routine training. However, the management of chronic diseases requires the empowerment of the patients in terms of disease management, care, and participation in the treatment. Therefore, these patients must receive comprehensive education about the disease, symptoms, and complications (especially the correct methods of self-care) in order to achieve the desired outcomes. Self-care education is an important task of nurses, which promotes healthy behavior. As a result, adult patients learn and take actions to maintain their survival, quality of life, and wellbeing. The feedback-based method is a client-oriented educational approach, which is often preferred over other educational methods. Assessing the proper understanding of the individuals toward the training materials provides feedback to ensure that they have received the training information accurately and completely, which has a significant impact on the quality of self-care and patient satisfaction with the treatment and care. The main complaints of patients with rheumatoid arthritis are pain and sleep disorders, along with daily symptoms, fatigue, drowsiness, depression, mood and cognitive disorders, decreased concentration, and anxiety. Therefore, it is paramount to evaluate the impact of self-care education on the pain management and sleep disorders of these patients. The present study aimed to investigate the effects of feedback-oriented self-care training on the pain intensity and sleep quality of patients with rheumatoid arthritis. We also compared sleep quality and pain intensity before and after the intervention with the assumption that sleep quality would improve and pain intensity would decrease after the intervention.

Materials \& Methods: This study was conducted based on the one-group evaluation of effect with a pretestposttest design, in which we evaluated the effects of self-care training by the feedback method on the pain intensity and sleep quality of the patients with rheumatoid arthritis referring to the rheumatology clinic of Imam Reza (AS) Hospital in Amol city, Iran. The study was performed during one year (August 2019-July 2020), and 60 patients were selected via continuous sampling within six months (October 2019-April 2020) considering attrition. Four patients were also excluded. The inclusion criteria were rheumatoid arthritis diagnosed by a physician, age of 1860 years, at least one year of disease history, complaints of pain and poor sleep quality (scores $>5$ ), basic literacy, awareness of time and location, ability to understand the Persian language, and no psychological disorders based on medical records. The exclusion criteria were employment in the health system, other chronic diseases (e.g.,
\end{abstract}

\footnotetext{
1. Master of Medical-Surgical Nursing, School of Nursing and Midwifery, Iran University of Medical Sciences, Tehran, Iran.

${ }^{2}$. Nursing Care Research Center, Department of Pediatric Nursing, School of Nursing and Midwifery, Iran University of Medical Sciences, Tehran, Iran (Corresponding author) kashaninia.za@iums.ac.ir

${ }^{3}$. Nursing Care Research Center, Department of Medical-Surgical Nursing ,School of Nursing and Midwifery, Iran University of Medical Sciences, Tehran, Iran.

${ }^{4}$. Department of Biostatistics, School of Health, Iran University of Medical Sciences, Tehran, Iran
} 
cardiovascular diseases, asthma, cancer, and mental illnesses), using psychotropic drugs, absence in one training session, and unwillingness or the impossibility of continuing participation. The training was implemented in three sessions using the feedback method. At the pre-training stage and one month post-training, data were collected using the Pittsburgh visual pain scale and sleep quality index, which were completed and compared. Data of 56 patients were analyzed in SPSS version 16 using descriptive statistics, paired t-test, and Wilcoxon test at the significance level of $\mathrm{P}<0.001$.

Results: The mean age of the subjects was $45.04 \pm 8.83$ years. The majority of the patients $(89.3 \%)$ were female, married $(87.5 \%)$, had an undergraduate degree $(71.5 \%)$, and poor economic status $(71.4 \%)$. In addition, $32.1 \%$ were unemployed, $55.3 \%$ were housewives, $58.9 \%$ had no history of other diseases, and $64.3 \%$ had a history of surgery. Also, $64.3 \%$ of the patients had a family history of rheumatoid arthritis, and $35.7 \%$ the duration of the disease to be 6-10 years. The highest involvement was with the joints of the upper torso (55.4\%), while $76.8 \%$ of the patients did not use sleeping pills, $92.9 \%$ did not smoke, and $96.4 \%$ did not consume alcohol. Before the intervention, the sleep quality of the majority of the patients $(96.4 \%)$ was poor. After the intervention, the sleep quality of the majority (92.9\%) was observed to be favorable, and the sleep quality scores in all the domains were significantly lower after the intervention compared to before the intervention $(\mathrm{P}<0.001)$. According to Table 4 , pain intensity was high in $58.9 \%$ of the subjects before the intervention, and none of the patients had low pain intensity. After the intervention, the majority (67.9\%) experienced moderate pain intensity, and high pain intensity was observed in none of the subjects. Furthermore, the mean pain intensity score was significantly lower after the intervention compared to before the intervention $(\mathrm{P}<0.001)$.

Conclusion: According to the results, feedback-based training could reduce pain intensity and improve sleep quality in the patients with rheumatoid arthritis. Considering the key role of education in the empowerment of patients with chronic diseases, it is suggested that feedback-based educational approaches be used along with other training methods in order to decrease pain intensity, improve sleep quality, and increase the satisfaction of rheumatoid arthritis patients.

Keywords: Sleep Quality, Pain Intensity, Self-care Education, Feedback-based Method, Rheumatoid Arthritis

\section{Conflict of Interest: No}

How to Cite: Latifi Shahandashti SR, Kashaninia Z, khachian A, Haghani H. Effects of the Teach-back Method of Self-care Education on the Pain Intensity and Sleep Quality of Rheumatoid Arthritis Patients. Iran Journal of Nursing. 2021; 34(129): 15-26.

Received: 4 Jan 2021

Accepted: 5 Apr 2021 


\section{ارزشيابى اثر آموزش خود مراقبتى به روش بازخورد محور بر شدت درد و كيفيت خواب افراد مبتلا به آرتريت روماتوئيد}

سيده ربابه لطيفى شاهاندشتى '، زهرا كاشانى نيا؟، آليس خاجيان 'ّ، حميد حقانىع

جكيuه

زمينه و هدف: آرتريت روماتوئيد بيمارى مزمن، التهابى و خود ايمنى ييشرونده با علائم بالينى متغيراست، كه مىتواند علت اصلى ناتوانى، كوتاهى عمر

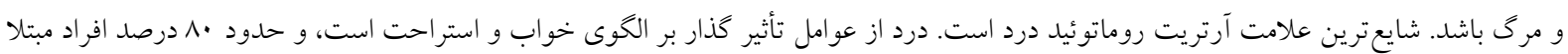

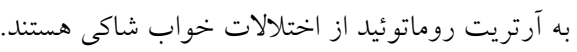

روش بررسى: مطالعه حاضر از نوع ارزشيابى اثر، تك گروهى با انجام بيش آزمون و يس آزمون است، كه طى آن اثر آموزش خود مراقبتى به روش

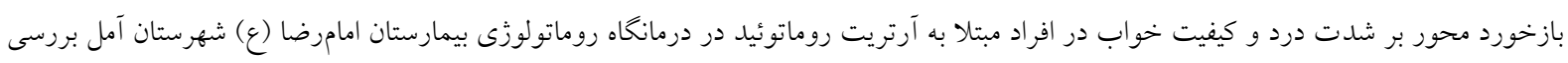

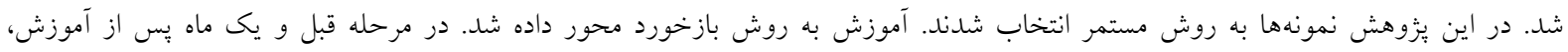

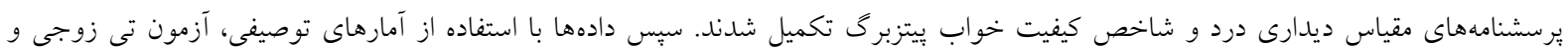

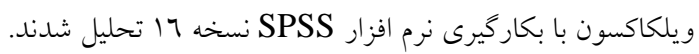

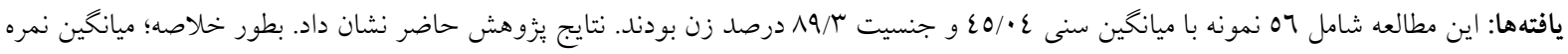

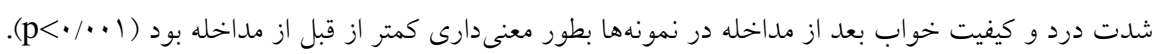

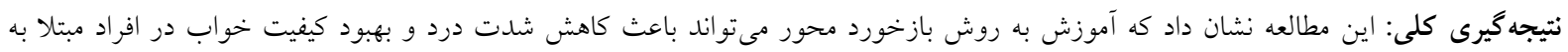

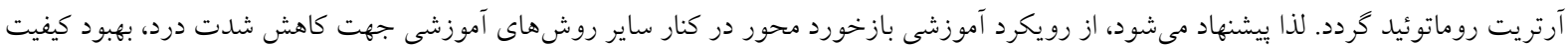
خواب و افزايش رضايتمندى افراد مبتلا به آرتريت روماتوئيد استفاده كرد.

كليل وازهها: كيفيت خواب، شدت درد، آموزش خود مراقبتى، روش بازخورد محور، آرتريت روماتوئيد.

تعارض منافع: وجود ندارد.

تاريخ دريافت: 99/1/10

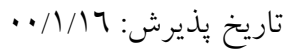

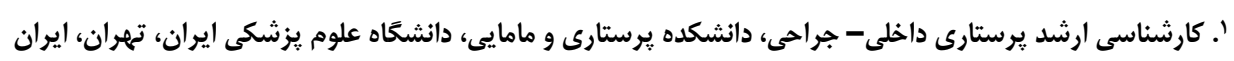

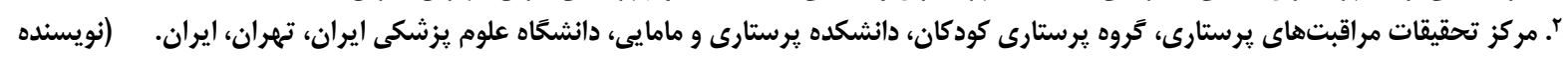

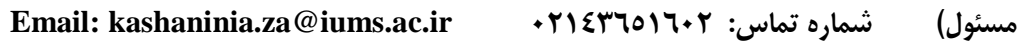

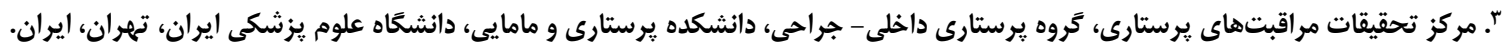

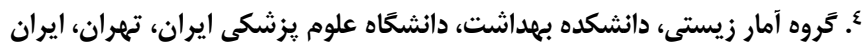


از اين تعداد حدود • ا درصد افراد مبتلا به معلوليت شديد

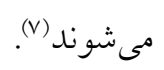

درد شايعترين علامت آرتريت روماتوئيد است. درد از علل شايع نخر انى بشر است. طبق برآوردها •م درصد مر مراجعه

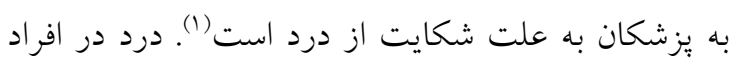

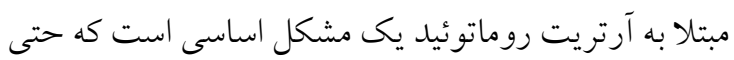

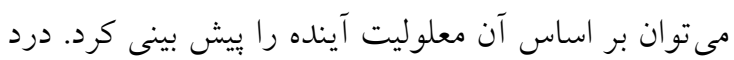

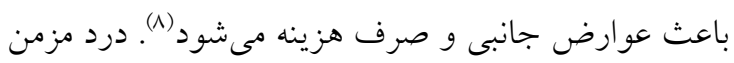

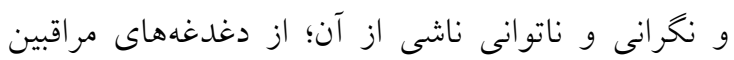

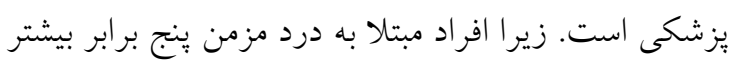
از ساير افراد جامعه از خدمات مراقبتهاى بهداشتى اوليه

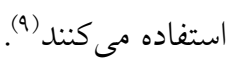
از طرفى ارتباط بين دردهاى بدنى و اختلالات خواب

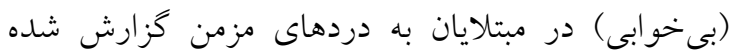

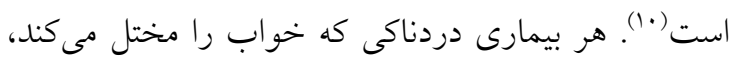

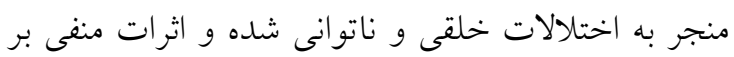

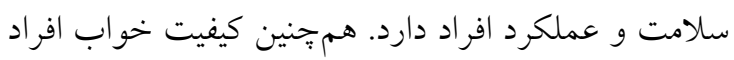

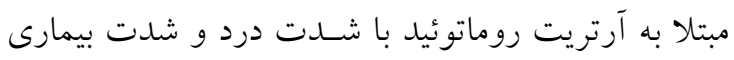

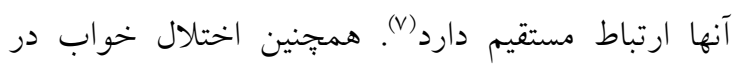
بيمارى هاى مزمن شايع است و حدود •^م درصد افر اد مبتلا

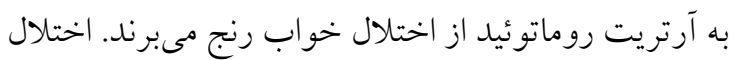
خواب باعث تشديد علائم بالينى بيمارى از جمله درد

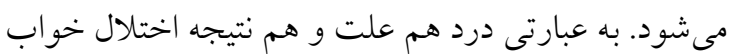
(11) (11) در (•V-0/\%) افراد مبتلا به آرتريت روماتوئيد خواب

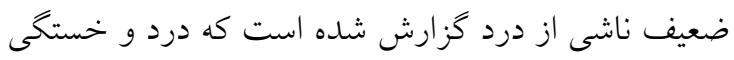
را افزايش مىدهد. خواب ضعيف علاوه بر خستكى، درد، افسردگى و التهاب با اختلالات خلقى همر اه است و موجب لقد افزايش خطر ابتلا به بيمارىهايى مانند خاقى، فشارخون

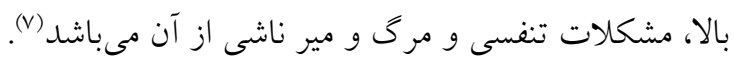
مديريت بيمارىهاى مزمن نيازمند توانمندسازى افراد در امر مديريت، مراقبت و مشاركت در درمان است. بنابراين اين افراد براى حصول نتايج مطلوب، نيازمند به دريافت آموزش جامع در مورد علائم و عوارض بيمارى هستند (Ir).
مقدمه آرتريت روماتوئيد يك بيمارى مزمن است و برآورد

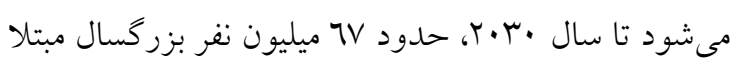

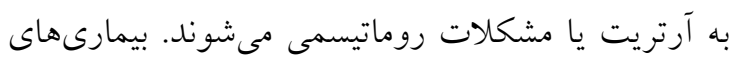

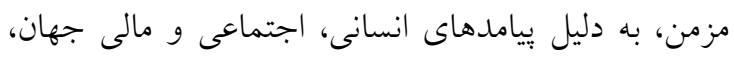
يكى از جالشهاى بزرى سلامتى قرن حاضر هستند (1).

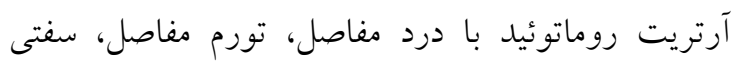

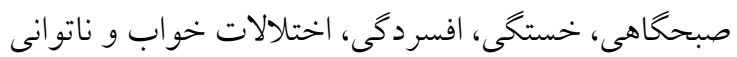
شناخته مى شود (r). طبق آمار سازمان بهاشت جناش جهانى بر اساس مطالعات

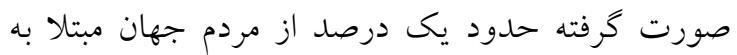

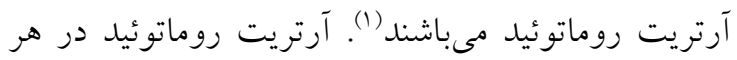
سنى بروز بيدا مى كند ولى گروه سنى 0ب-0.0 سال بيشتر

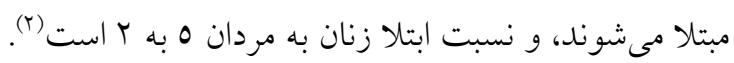

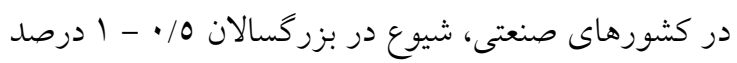

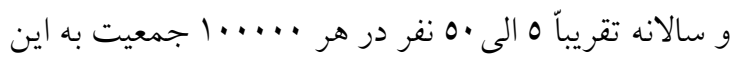
بيمارى مبتلا مى شوند. ابتلا زنان به آرتريت روماتوئيد مانند

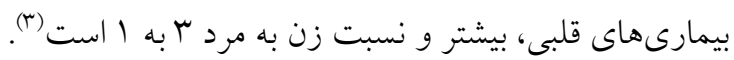

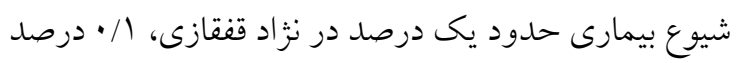

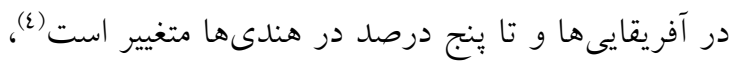

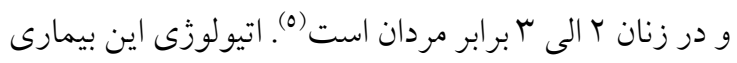

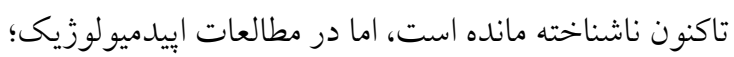
فاكتورهاى زنتيكى و محيطى را به صورت توأم در ابتلا به ناته

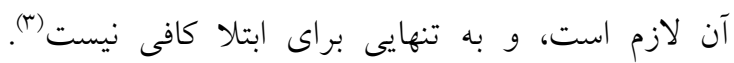
همجنين بيمارى هاى مفصلى و استخوانى خصوصاً آرتريت

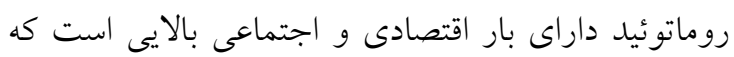

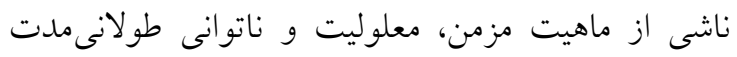

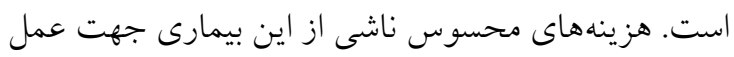

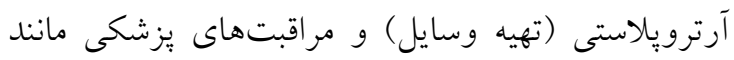

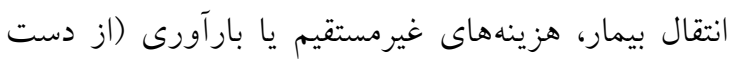

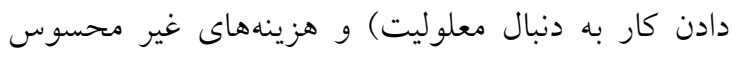

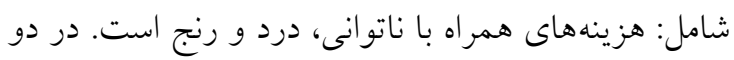

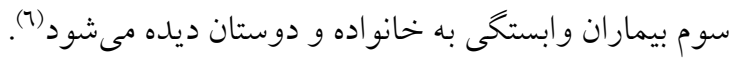




\section{روش بررسى}

مطالعه حاضر يك مطالعه ارزشيابى اثر آموزش به روش روش

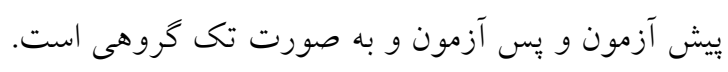

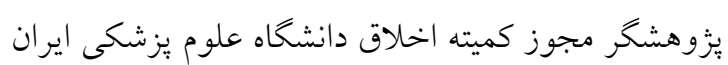
(IR.IUMS.REC.1398.594)

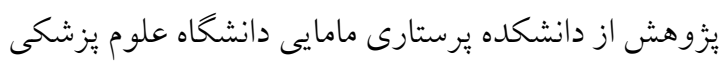
ايران را كسب نمود. معيارهاى ورود به مطالعه شامل ابتلا

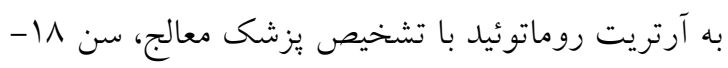

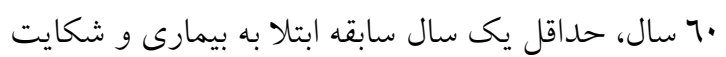

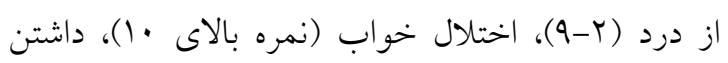

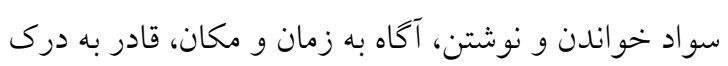

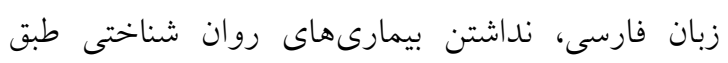

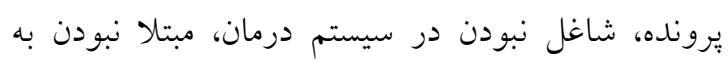

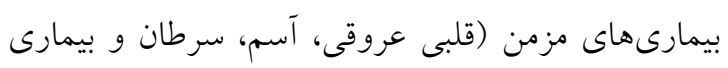

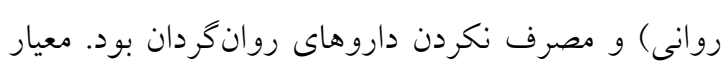

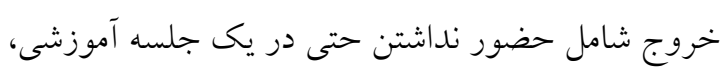

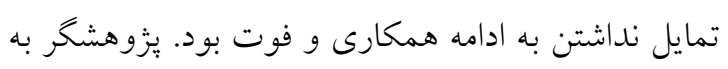

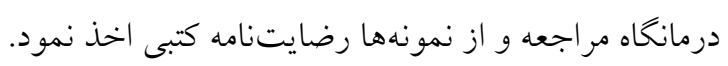

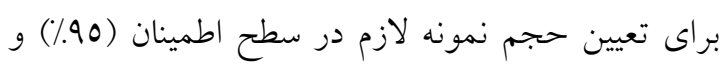

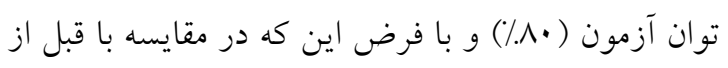

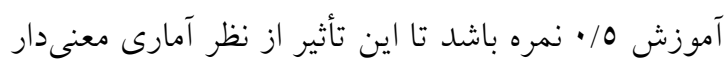

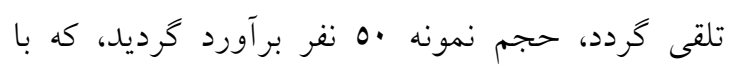

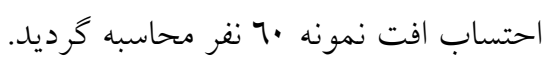

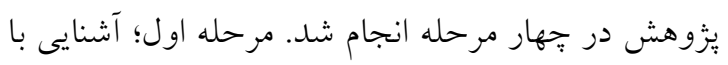

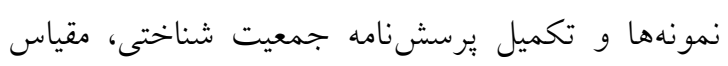

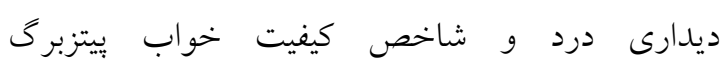
(Pittsburgh sleep quality index) خودخزارشدهى توسط نمونهها (اولين مرحله گردآورى

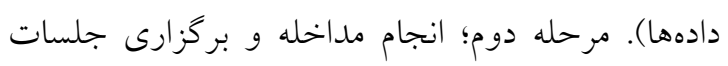

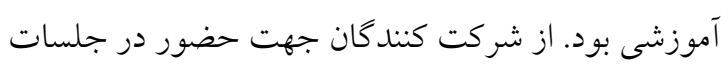
دعوت شد. روند جلسات آموزشى براى هر فرد شامل سه آه

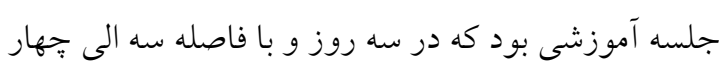

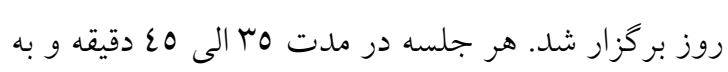
صورت انفرادى و به روش بازخورد محور در درمانحاه
آموزش افراد مبتلا به بيمارىهاى مزمن مانند آرتريت

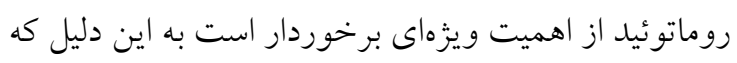

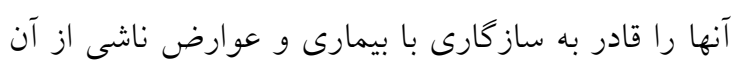
و همجنين تطابق با درمانهاى مختلف مىنمايد (rان).

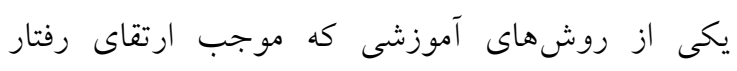

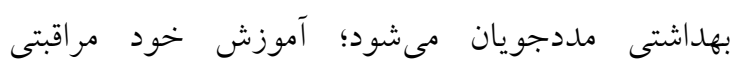
است (1) (1) خود مراقبتى عملى است كه در آن هر فردى از دانش،

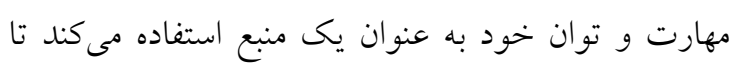

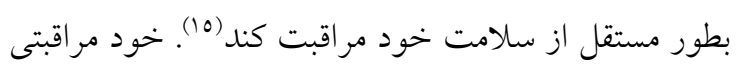

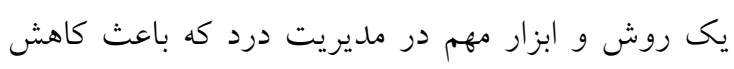

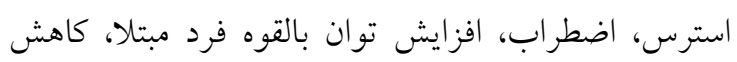
هزينه و ارتقا سلامت است (^). يكى از روشهاى مددجو محور در آموزش، روش رئن

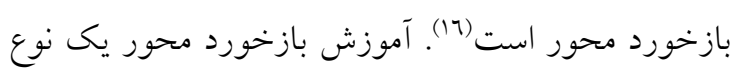

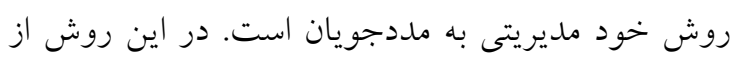

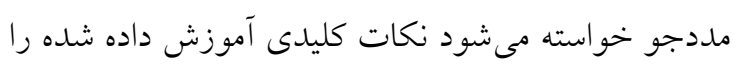

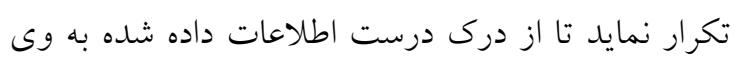

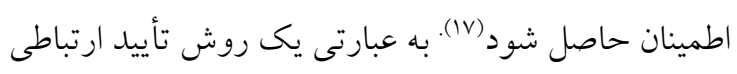

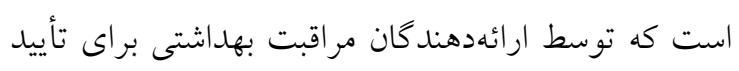

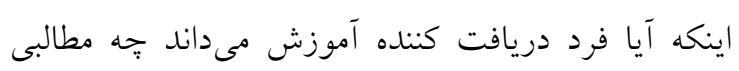

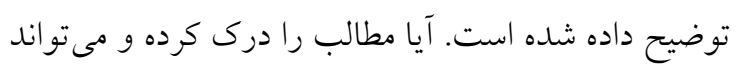
اطلاعات را به درستى بازخورد دهد (17).

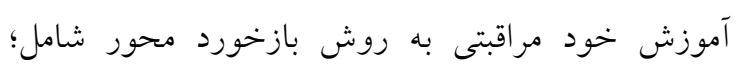

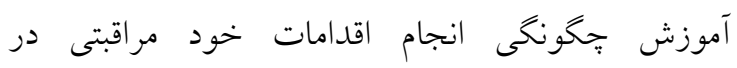

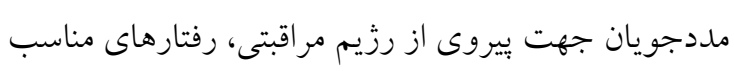

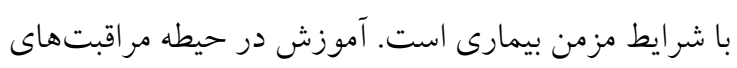

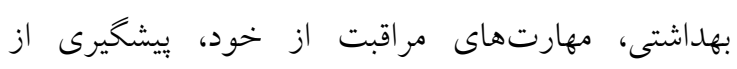

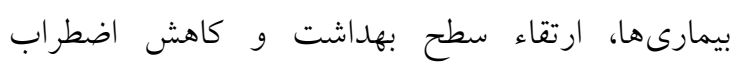

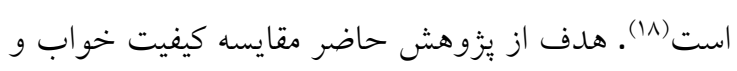

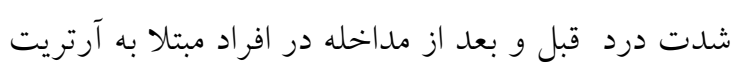

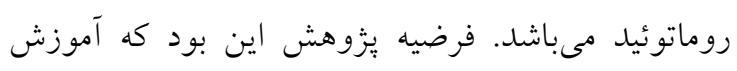

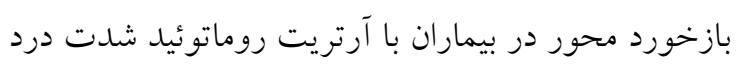

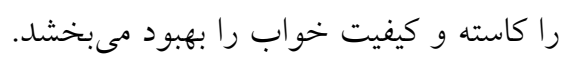


7= درد متوسط، V الى 9= درد زياد و • شديدترين درد) است. از نمونهها درخواست شد تا بر نقطهاى از ابزار كه نشان دهنده شدت درد ايشان است علامت كذارى كنند (^).

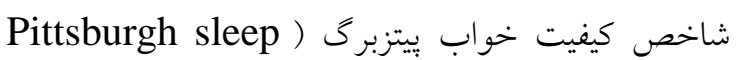
quality index كلى فرد از كيفيت خواب r- اختلال عملكرد روزانه(19). اين برسشنامه در اصل داراى 9 گويه است اما جون سؤال

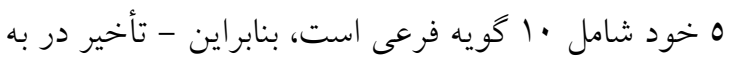
خواب رفتن r- طول مدت خواب مفيد ع- خواب مفيد 0- اختلالات خواب 7- ميزان داروى خوابآورمصرفى Vكل برسشنامه داراى 19 گويه است كه در يك طيف ليكرت ع درجهاى از · تا س نمرهذارى مىشود. نمره هر يك از مقياسها در برسشنامه بين ب- · در نظر كرفته شده است. به اين صورت كه نمره · (مشكل ندارد)، نمره ا (بندرت مشكل دارد)، نمره Y (مشكل دارد)، نمره r (مشكل جدى دارد) كه تمامى نمونهها دو بار برسشنامه را قبل و بعد از مداخله (به فاصله يك ماه يس از اتمام) تكميل خواهند كرد

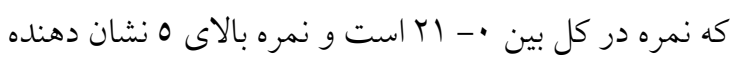
كيفيت بايين خواب است (19). روايى زبرسشنامه كيفيت خو اب بيتزبرى يس از ترجمه يرسش بامه انخليسى شاخص كيفيت خواب ييتزبرى، تنظيم و ارائه شد، و توسط اعضاء هيئت علمى تيم يزوهش دانشكده برستارى و مامايى

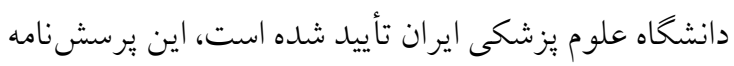
در متون براى ارزيابى خواب در افراد مبتلا به آرتريت روماتوييد استفاده شده است. و بِيايى آن براى جمعيت

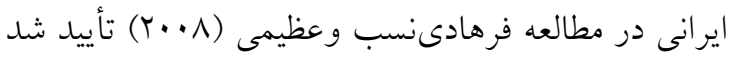
كه ازحساسيت 19/7 درصد و ويزگى 1/70 درصد

$$
\text { برخوردار بود (ع). }
$$

در نهايت با احتساب جهار نفر در ريزش نمونه، دادههاى 07 نفر با بكاركيرى آزمونهاى تى زوجى و ويلكاكسون و با استفاده از نرم افزار SPSS نسخه 17 مورد تجزيه و تحليل قرار كرفت.
بيمارستان امام رضا (ع) برگزار شد. محتواى مطالب آموزشى به ترتيب ذيل ارائه كرديد. جلسه اول؛ درباره ماهيت بيمارى آرتريت روماتوئيد (علل، مراحل، عوارض له له و درمان) و آموزش هاى معمول طبق توصيه يزشك (رزيم درمانى)، جلسه دوم؛ در خصوص خود مراقبتى ( هدف از خود مراقبتى و خود مراقبتى در بيمارى آرتريت روماتوئيد و نتايج آن)، درد و مديريت درد (علت درد، علل افزايش درد، خود مراقبتى و مديريت درد) و خواب و مديريت خواب و در جلسه سوم؛ از جگحونكى و دليل انجام برنامه ورزشى به منظور حفظ دامنه حركت مفاصل، ايزومتريك (تقويت تون عضلات) و ديناميك توصيه شده در آرتريت روماتوئيد بود. مرحله سوم؛ بيخيرىهاى تلفنى در طى جهار هفته براى اطمينان از ادامه انجام خود مراقبتى، راهنمايى، رفع ابهامات و ياسخ به سؤالات نمونهها بود. مرحله جهارم، تكميل مجدد برسشنامههاى مقياس ديدارى درد و شاخص كيفيت خواب (يك ماه بعد از يايان مداخله) و جمع آورى دادهها بود. ابزار بزّوهش متشكل از سه برسشنامه؛ فرم اطلاعات جمعيتشناختى، مقياس ديدارى درد و شاخص كيفيت خواب ييتزبورى است. اطلاعات جمعيت شناختى شامل متغيرهاى فردى، جنس، سن (1/-70)، وضعيت تأهل (مجرد، متأهل، بيوه)، سطح تحصيلات، شغل، وضعيت اقتصادى، اطلاعات بيمارى شامل سابقه خانوادكى، طول مدت بيمارى، تعداد مفاصل درگير و مدت ابتلا (كمتر از 0 سال- از 0 تا • ( سال- بالاى •إل سال)، تعداد مفصل درگير (يكى، بيشتر از يكى) و نوع مفصل درگير (اندام فوقانى، اندام تحتانى، كمر و گردن) و سؤالات سبك زندكى، كشيدن سيخار، نوشيدن الكل، نوع اختلال خواب، مصرف داروى خوابآور، سابقه بيمارى ديخر و سابقه

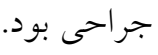

جAS جرت بررسى درد از مقياس افقى ديدارى درد

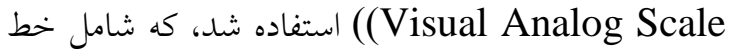
افقى ده سانتى مترى است كه نشاندهناه بيوستارى با انتهاى

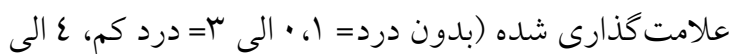




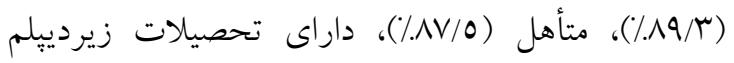

(VI/O) درصد بيكار و 00/ درصد خانهدار بودند. 0N/9 درصد

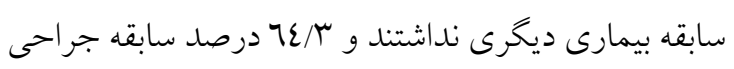
داشتند. ب/ع7 درصد در خانواده سابقه بيمارى آرتريت روماتوئيد داشتند. ro/V درصد طول مدت ابتلا بين 7 تا

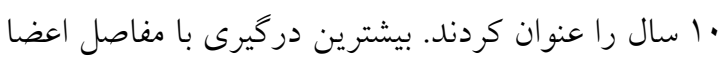

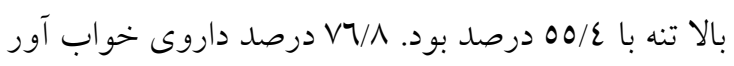

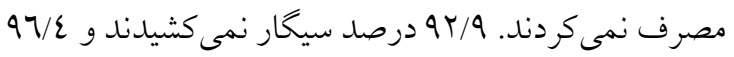
درصد مصرف نوشيدنى حاوى الكل نداشتند.

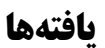

از •7 نفر؛ جهار نمونه در طى مداخله از مطالعه كنار

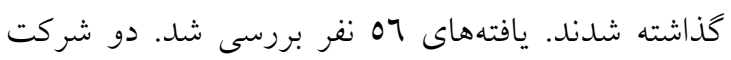

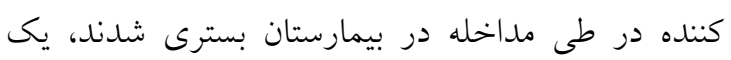

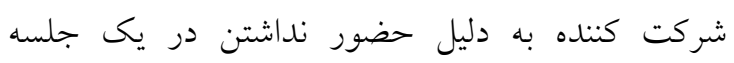
آموزشى و يك شركت كننده به دليل تكميل نكردن ابزار

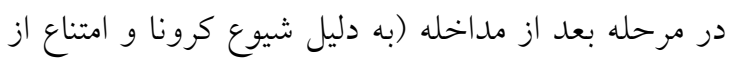

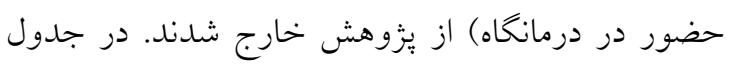

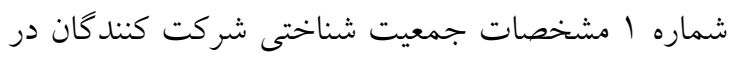
مطالعه خلاصه شده است. ميانخين سنى افراد مورد مطالعه

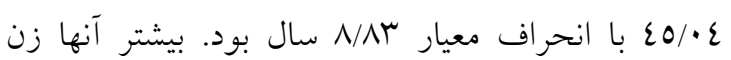

جدول شماره ا: توزيع فراوانى مشخصات جمعيت شناختى نمونهها

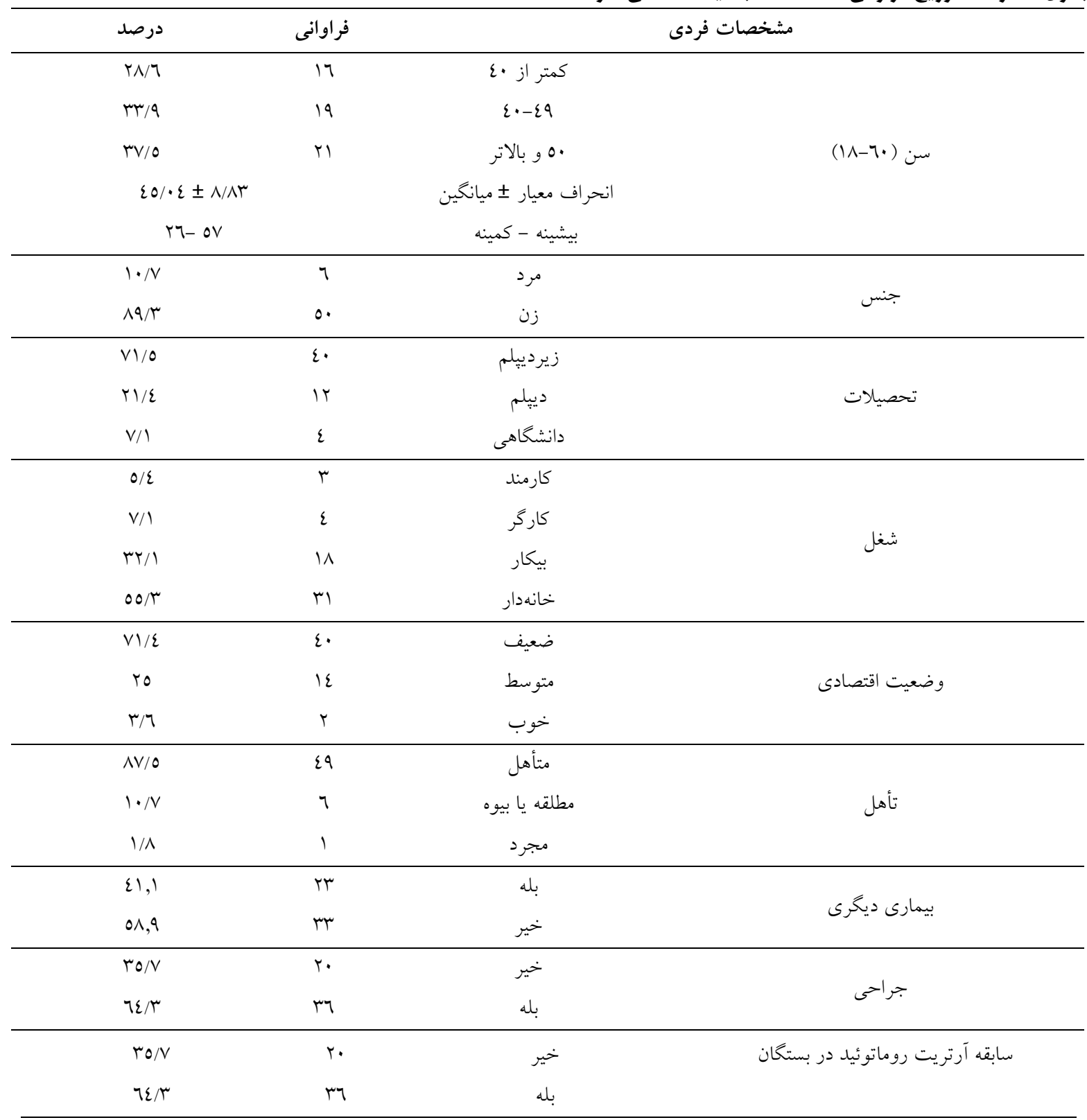




\begin{tabular}{|c|c|c|c|}
\hline$r \Lambda / 7$ & 17 & $0-1$ & \\
\hline ro/v & $r \cdot$ & $1 \cdot-7$ & طول مدت ابتلا \\
\hline $1 \varepsilon / \mu$ & $\wedge$ & $11-10$ & \\
\hline$r \mid / \varepsilon$ & ir & بالاى 17 & \\
\hline$r / 7$ & r & كردن & \\
\hline $00 / 2$ & r & قسمت بالاى تنه & مفاصل درگير \\
\hline$r q / r$ & rT & قسمت پيايين تنه & \\
\hline $1 / \wedge$ & 1 & 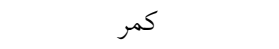 & \\
\hline ro/v & $r \cdot$ & هنخام به خواب رفتن & \\
\hline$\varepsilon \varepsilon / 7$ & ro & در حين خواب & اختلالات خواب \\
\hline $1 T / 0$ & v & نداشتن خواب خوب & \\
\hline $\mathrm{V} / \mathrm{l}$ & $\varepsilon$ & زود از خواب بيدار شدن & \\
\hline$\vee \mathrm{V} / \Lambda$ & $\varepsilon r$ & 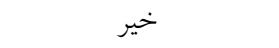 & دارو خوابآور \\
\hline$r M / T$ & $1 r$ & بله & \\
\hline $\mathrm{V} / \mathrm{l}$ & $\varepsilon$ & بله & سيخار \\
\hline $9 r / 9$ & Or & 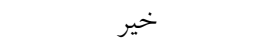 & \\
\hline$r / \tau$ & r & بله بله & مصرف الكل \\
\hline $97 / \pi$ & or & خير & \\
\hline
\end{tabular}

كيفيت خواب در سطح خوب داشتند. بر اساس آزمون تى زوجى ميانكين نمره كيفيت خواب بعد از مداخله كمتر از

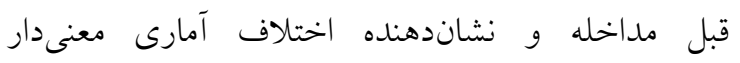
(p<•/•l)
براساس نتايج در جدول شماره Y ، ميانخين كيفيت خواب

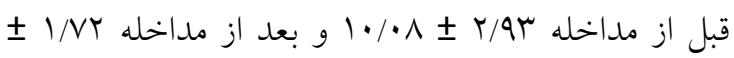

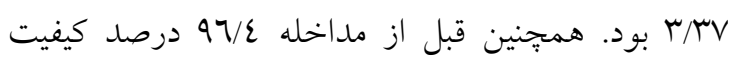

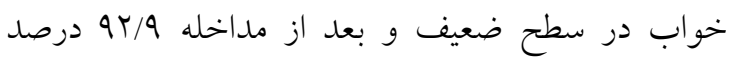

جدول شماره r: توزيع فراوانى نمره كل كيفيت خواب در نمونهها قبل و بعد از مداخله

\begin{tabular}{|c|c|c|c|c|c|}
\hline \multicolumn{2}{|c|}{ بعد } & \multicolumn{3}{|c|}{ قبل } & \multirow[t]{2}{*}{ كيفيت خواب } \\
\hline درصد & فراوانى & & درصد & فراوانى & \\
\hline $\mathrm{V} / \mathrm{I}$ & $\varepsilon$ & & $97 / 2$ & or & ضعيف \\
\hline $9 r / 9$ & or & & $r / 7$ & r & خوب \\
\hline $1 \ldots$ & 07 & & $1 \ldots$ & 07 & جمع كل \\
\hline \multicolumn{2}{|c|}{$r / r V \pm I / N r$} & \multicolumn{3}{|c|}{$1 \cdot / \cdot \wedge \pm r / q r$} & انحراف معيار \ميانكين \\
\hline \multicolumn{2}{|c|}{$\cdot-9$} & & \multicolumn{2}{|c|}{$\varepsilon-11$} & بيشينه-كمينه \\
\hline & $\mathrm{p}<\cdot / \cdot \cdot 1$ & $\mathrm{df}=00$ & $\mathrm{t}=r r / 1$ & & نتيجه آزمون تى زوجى \\
\hline
\end{tabular}

خوابآور و اختلالات عملكردى روزانه) بين قبل و بعد از مداخله است ( (p) ) كه به معناى بهبود كيفيت خواب مىباشد.
نتيجه آزمون ويلكاكسون در جدول شماره ب نشاندهنده اختلاف آمارى معنى دار مؤلفههاى خواب (كيفيت ذهنى

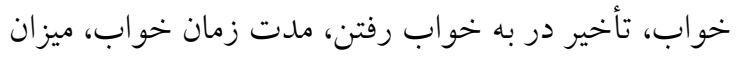

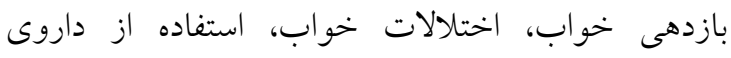


جدول شماره س: شاخصهاى عددى حيطههاى كيفيت خواب در نمونهها قبل و بعد از مداخله

\begin{tabular}{|c|c|c|c|c|c|c|c|c|c|}
\hline \multirow{2}{*}{ نتيجه آزمون } & \multicolumn{4}{|c|}{ بعد } & \multicolumn{4}{|c|}{ قبل } & \multirow[t]{2}{*}{ حيطه هاى كيفيت خواب } \\
\hline & انحر اف معيار & ميانخين & بيشينه & كمينه & انحر اف معيار & ميانخين & بيشينه & كمينه & \\
\hline $\mathrm{p}<\bullet / \cdots 1$ & תוא/ & $\cdot / \mathrm{AV}$ & 1 & . & $\cdot / 2 r$ & $r / \cdot V$ & $r$ & 1 & كيفيت ذهنى خواب \\
\hline $\mathrm{p}<\bullet / \cdots)$ & $\cdot 107$ & $\cdot 100$ & r & . & $\cdot / 91$ & $1 / \wedge$ & r & . & تأخير در به خواب رفتن \\
\hline $\mathrm{p}<\bullet / \cdots 1$ & $\cdot / 29$ & $\cdot / \mathrm{VI}$ & r & . & $\cdot / \mathrm{VV}$ & $1 / \pi V$ & r & . & مدت زمان خواب \\
\hline $\mathrm{p}<\bullet / \cdot \cdot 1$ & $\cdot / 4 q$ &.$/ 1 r$ & r & . & $\cdot / 9 r$ & $\cdot / 91$ & r & . & ميزان بازدهى خواب \\
\hline $\mathrm{p}<\cdot / \cdots 1$ & $\cdot /$ TO & $\cdot / 9 r$ & 1 & . & $\cdot 10 \mathrm{~V}$ & $1 / V 7$ & r & 1 & اختلالات خواب \\
\hline $\mathrm{p}<\bullet / \cdot \bullet$ & $\cdot 10 \mathrm{~V}$ & $\cdot / 1 \wedge$ & r & · & $1 / \cdot r$ & $\cdot 10 \mathrm{~V}$ & $r$ & · & استفاده از داروهاى خوابآور \\
\hline $\mathrm{p}<\bullet / \cdots)$ & $\cdot /$ ro & $\cdot / \varepsilon$ & 1 & . & $\cdot / \wedge \mathrm{V}$ & $1 / 01$ & r & . & اختلالات عملكردى روزانه \\
\hline
\end{tabular}

يزؤهش حاضر يافت نشد. مطالعاتى در زمينه اختلال خواب، كيفيت خواب و كاهش درد در افراد مبتلا به آرتريت روماتوئيد و روش آموزشى بازخورد محور در بيمارىهاى مزمن انجام شده بود كه نتايج آنها با مطالعه حاضر مقايسه شد. نتايج مطالعه حاضر نشان داد كه آموزش مرث بازخورد محور بر كاهش شدت درد و بهبود كيفيت خواب موثر بود. در مطالعه حاضر كيفيت خواب در همه حيطهها بعد از مداخله به طور معنىدارى كمتر از قبل از مداخله بود، كه به معناى بهبود كيفيت خواب است. در مطالعه Irwin كم خو ابى و تشديد خستخى، افسردگى و درد در افراد مبتلا به آرتريت روماتوئيد انجام كرفت؛ كيفيت خواب افر اد مبتلا

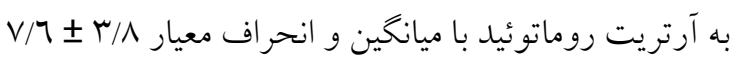
بود (19). در مطالعه عباسى و همكاران در قزوين كه با عنوان رابطه كيفيت خواب با بيمارى آرتريت روماتوئيد و شدت آن انجام كرفت • V درصد مبتلايان به آرتريت روماتوئيد خو اب با كيفيت ضعيف داشته و مربوط به اختلال در حين خواب بود (ع). در مطالعه يور عبدالله و همكار ان كه در تبريز

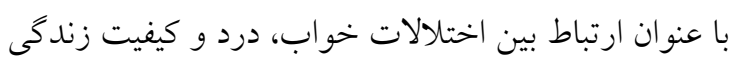
در افراد مبتلا به آرتريت روماتوئيد انجام شد. ميانخين كيفيت خواب در افراد مبتلا به آرتريت روماتوئيد

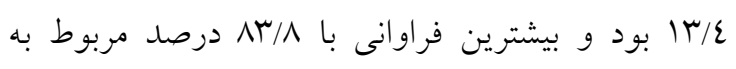

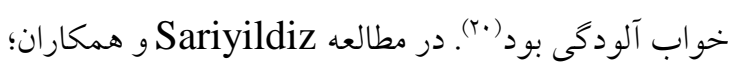
در تركيه كه با عنوان كيفيت خواب در آرتريت روماتوئيد:
براساس نتايج در جدول شماره ع؛ ميانخين شدت درد قبل

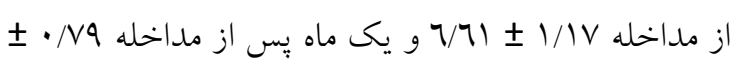

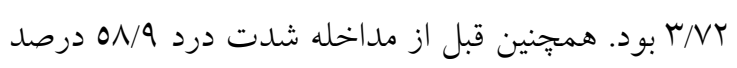

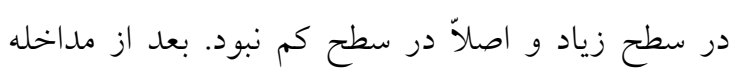
شدت درد 7V/9 درصد در سطح متوسط بود، و اصلاً درد در سطح زياد نبود. بر اساس آزمون تى زوجى ميانخين نمره درد بعد از مداخله كمتر از قبل مداخله بود كه نشان دهنده كاهش شدت درد و اختلاف آمارى معنىدار است

$$
(\mathrm{p}<\cdot / \cdot 1)
$$

جدول شماره ع: توزيع فراوانى شدت درد در افراد مبتلا به

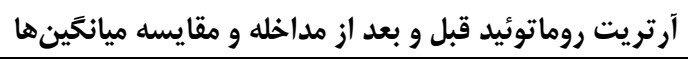

\begin{tabular}{|c|c|c|c|c|}
\hline \multicolumn{2}{|c|}{ بعد } & \multicolumn{2}{|c|}{ قبل ق } & \multirow[t]{2}{*}{ شدت درد } \\
\hline درصد & فراوانى & درصد & 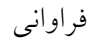 & \\
\hline$r T / l$ & 11 & · & $\cdot$ & كم \\
\hline $7 V / 9$ & щ & $\sum \ / 1$ & $r \mu$ & متوسط \\
\hline • & • & $0 \wedge / 9$ & r & زياد \\
\hline $1 \cdots$ & 07 & $1 \cdots$ & 07 & جمع كل \\
\hline \multicolumn{2}{|c|}{$r / V T \pm \cdot / V q$} & \multicolumn{2}{|c|}{$7 / 71 \pm 1 / 1 V$} & انحراف معيار 土 ميانخين \\
\hline \multicolumn{2}{|c|}{$r-7$} & \multicolumn{2}{|c|}{$\varepsilon-9$} & بيشينه -كمينه \\
\hline $\mathrm{p}<\bullet / \cdot$ & $\mathrm{df}=00$ & & $r V / \backslash \varepsilon O$ & نتيجه آزمون تى زوجى \\
\hline
\end{tabular}

\section{بحث و نتيجه تيرى}

مطالعه حاضر در درمانحاه روماتولوزى بيمارستان امامرضا (ع) آمل و بر روى افراد مبتلا به آرتريت روماتوئيد با دماهيا اختلال خو اب انجام شد. مطالعه مشابه براى مقايسه با نتايج 
خودكارآمدى و سبك زندگى ارتقاء دهنده سلامت در گروه

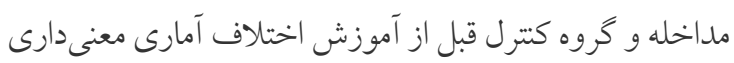

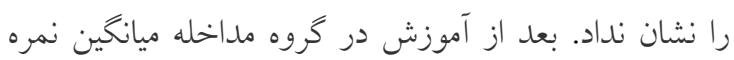
خودكارآمدى و سبك زندگى ارتقاء دهنده سلامت از نظر آمارى به طور معنى دارى بيشتر از گروه كتترل بوده است.

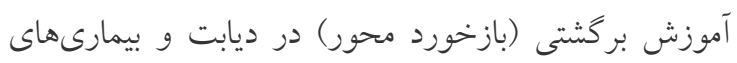
مزمن روشى عملى بوده و براى توانمندسازى بيماران امرى

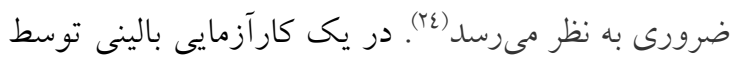

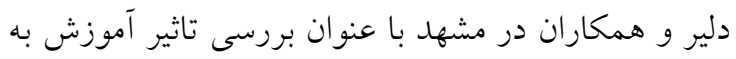
روش بازخورد محور بر خود كار آمدى و خود مر اقبتى افراد

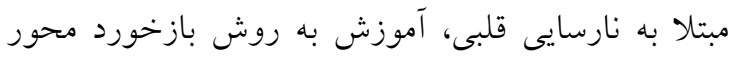
نسبت به آموزش مرسوم در جهت ارتقاء خود كارآمدى و خود مراقبتى بيماران با نارسايى قلبى مؤثرتر بودان(ro) در

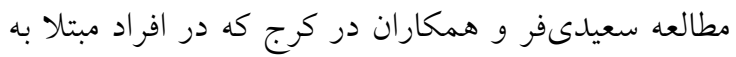

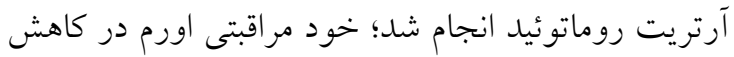

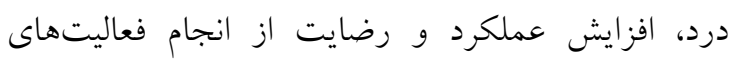

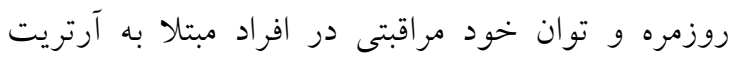

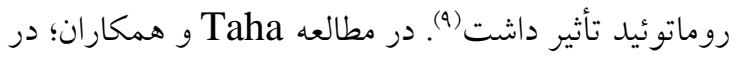

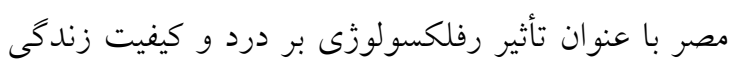

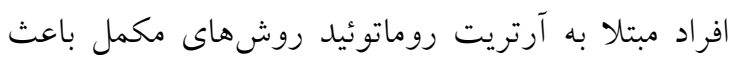
كاهش درد و بهبود كيفيت زندگى و وضعيت سلامتى آنها

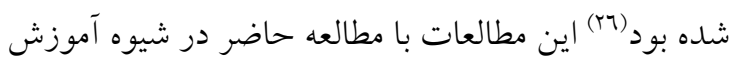

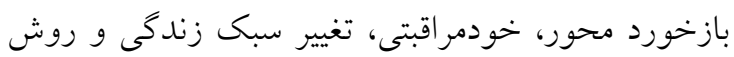

مكمل در توانمند سازى و كاهش درد مشابه است. در مطالعه Austad و همكاران در افراد مبتلا به آرتريت

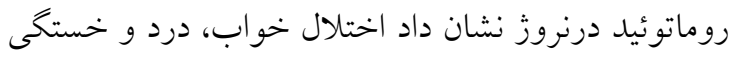
با هم رابطه متقابل داشته يعنى اختلال خواب ايجاد درد و

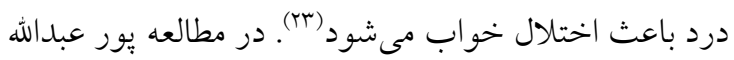

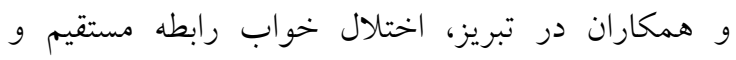

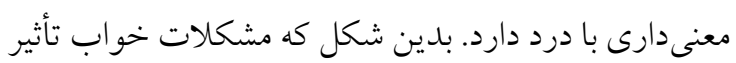
منفى بر سلامت و عملكرد داشته و موجب افزايش شدت

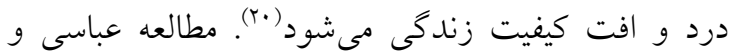

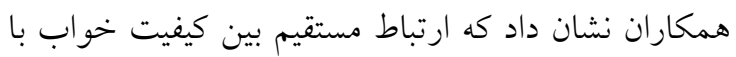
شدت درد و شدت بيمارى است. به طورى كه با افزايش
رابطه بين شدت بيمارى، افسردگى، وضعيت عملكردى و

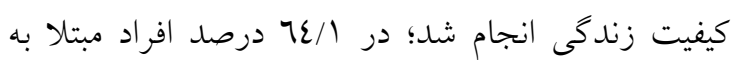

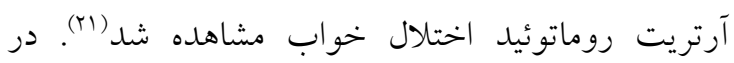

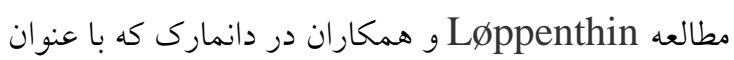
اثر ورزش هوازى متناوب بر اختلالات خواب و كيفيت

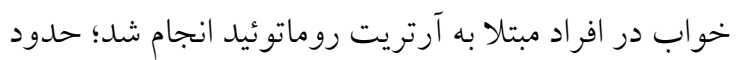

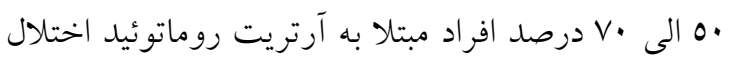

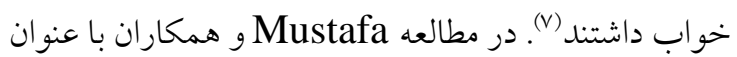

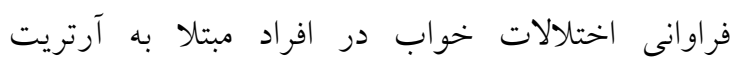
روماتوئيد كه در عربستان سعودى انجام شد، VT درصد از

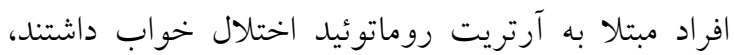

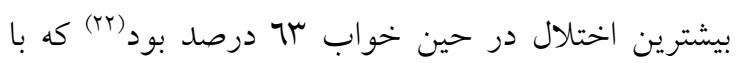

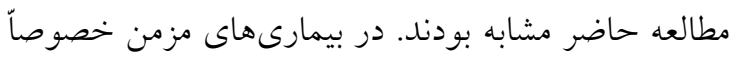

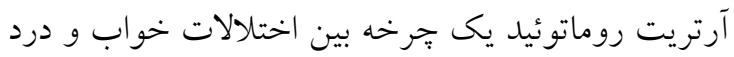

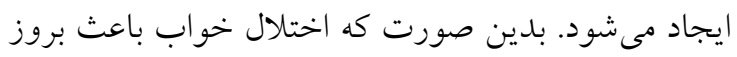

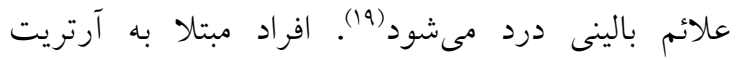

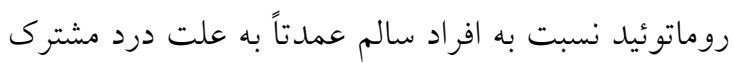

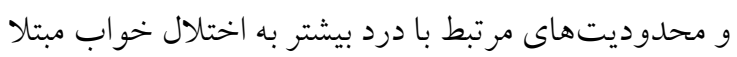

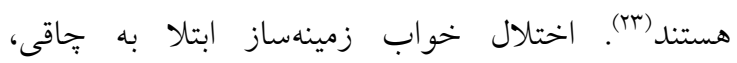

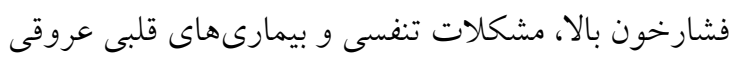

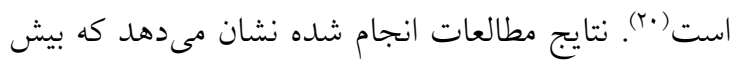
از 70- • درصد افراد مبتلا به آرتريت روماتوئيد اختلال خواب دارند، و بيشترين اختلال خواب مربوط به حين

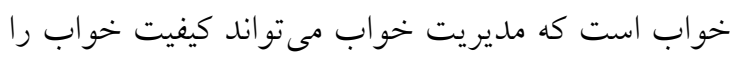
ب.f.ود دهل. در مطالعه حاضر آموزش خود مراقبتى به روش بازخورد محور در مديريت درد باعث كاهش شدت درد شد. در بدو مطالعه بيشتر مددجويان درد در سطح زياد داشتند و درد كم نداشتند ولى بعد از مداخله اصلاً درد در سطح زياد

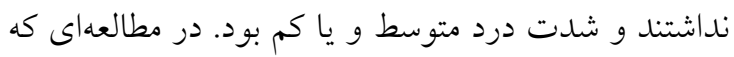

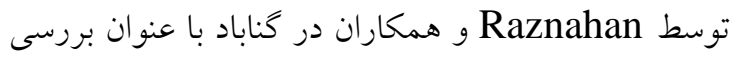

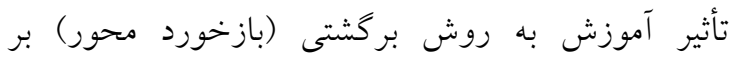

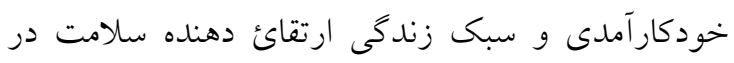
افراد داراى ديابت نوع دو انجام شد، ميانخين نمرات 
يكى از محدوديتهاى اين يزوهش بررسى نشدن اجراى

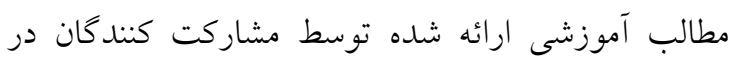
مطالعه در منزل بود كه ييشنهاد مىشود در مطالعات بعدى بدين منظور جى ليستى طراحى شده تا تبعيت بيمار از

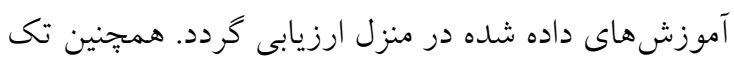
كروهى بودن و تعداد محدود نمونه نيز از ديخر محدوديتهاى اين يزّوهش بودند.

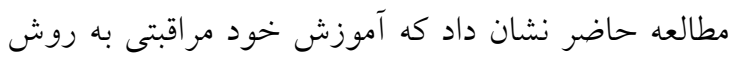
بازخورد محور بر كاهش شدت درد و بهبود كيفيت خواب

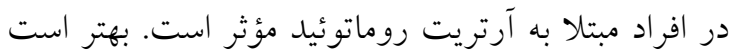
براى تأييد اثربخشى روش آموزشى بازخورد محور، مبها

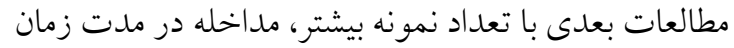
طولانى تر و به روش دو گروهى و بيشتر انجام شود.

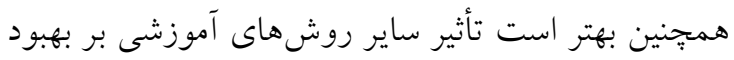

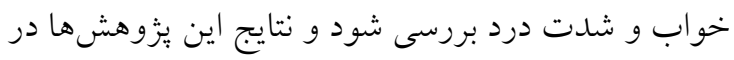
مراكز آموزشى و درمانى مورد استفاده دانشجويان و يرسنل يرستارى قرار كيرد.

تعارض منافع: هيج گونه تعارض منافع توسط نويسندكان

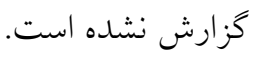

\section{تقدير و تشكر}

از مسئولين دانشكده يرستارى و مامايى دانشخاه علوم يزشكى ايران و مازندران و شبكه بهداشت و درمان و

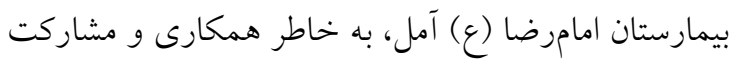

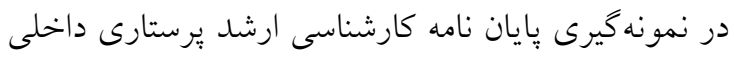

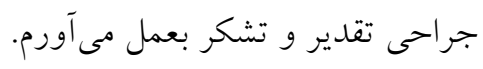

شدت بيمارى، درد افزايش يافته وكيفيت خواب بدتر

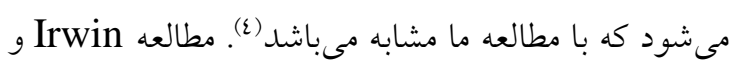

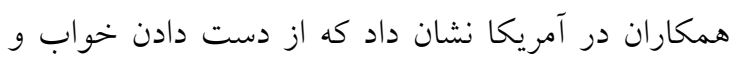
اختلالات خواب باعث تشديد علائم بالينى و درد باعث از دست دادن خواب بيشتر مىشود. در مبتلايان به بيمارى مزمن يك جرخه بين اختلالات خواب و درد درد ايجاد مى شود. بدين صورت كه اختلال خواب باعث بروز علائم

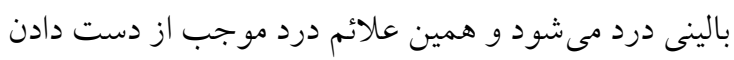

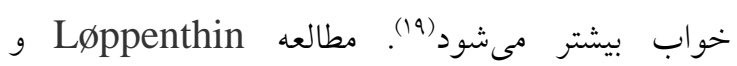
همكاران در دانمارك نشان دادكيفيت خواب افراد مبتلا به

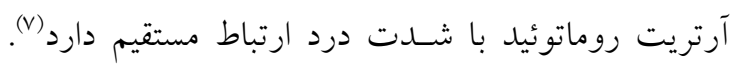
مطالعه Grabovac و همكاران در بيمار ان مبتلا به آرتريت روماتوئيد دراستر اليا نشان داد؛ اختلال خواب باعث تشديد علائم بالينى بيمارى از جمله درد مىشود. به عبارتى درد درد هم علت و هم نتيجه اختلال خواب است (11) مطالعه

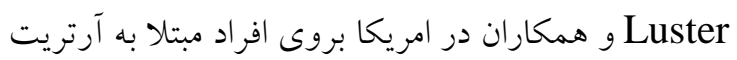

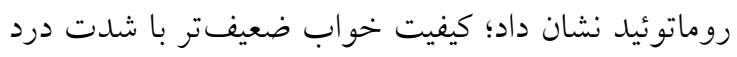
بيشتر همراه است و هنخام فعال شدن بيمارى التهابى با باني

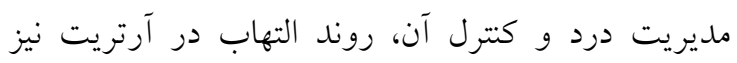

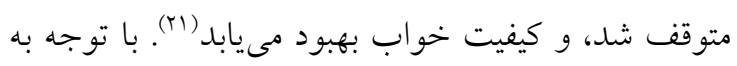
تأثيرى كه درد بر كيفيت خواب در افراد مبتلا به آرتريت روماتوئيد مى خذارد، ضرورى است براى بر ارتقائئ كيفيت

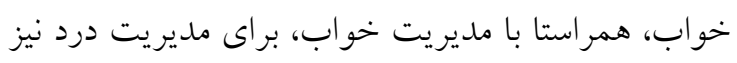

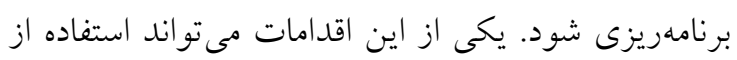

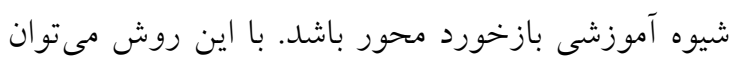

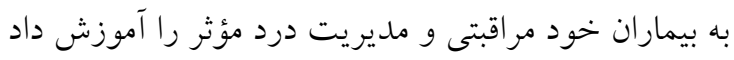
تا متعاقباً اختلال خواب را تجربه نكنند.

\section{References}

1. Hinkle JL, Cheever KH. Brunner and Suddarth's textbook of medical-surgical nursing. Wolters kluwer india Pvt Ltd; 2018 Aug 30.

2. Sariyildiz MA, Batmaz I, Bozkurt M, Bez Y, Cetincakmak MG, Yazmalar L, Ucar D, Celepkolu T. Sleep quality in rheumatoid arthritis: relationship between the disease severity, depression, functional status and the quality of life. J Clin Medic Res. 2014;6(1):44.

3. Chancay MG, Guendsechadze SN, Blanco I. Types of pain and their psychosocial impact in women with rheumatoid arthritis. Women's midlife health. 2019;5(1):1-9.

4. Krol B, Sanderman R, Suurmeijer TP. Social support, rheumatoid arthritis and quality of life: concepts, measurement and research. Patient Educ Counsel. 1993;20(2-3):101-20. 
5. Sullivan PW, Ghushchyan V, Huang XY, Globe DR. Influence of rheumatoid arthritis on employment, function, and productivity in a nationally representative sample in the United States. J Rheumatol. 2010;37(3):544-9.

6. Harjacek M, editor. Challenges in Rheumatology. BoD-Books on Demand; 2011 Dec 22.

7. Løppenthin K, Esbensen BA, Jennum P, Østergaard M, Christensen JF, Thomsen T, Bech JS, Midtgaard J. Effect of intermittent aerobic exercise on sleep quality and sleep disturbances in patients with rheumatoid arthritis-design of a randomized controlled trial. BMC musculoskeletal disorders. 2014;15(1):1-8.

8. Saeedifar ES, Memarian R, Fatahi S, Ghelichkhani F. Use of the Orem self-care model on pain relief in women with rheumatoid arthritis: a randomized trial. Electronic physician. 2018;10(6):6884.

9. Bawa FL, Mercer SW, Atherton RJ, Clague F, Keen A, Scott NW, Bond CM. Does mindfulness improve outcomes in patients with chronic pain? Systematic review and meta-analysis. $\mathrm{Br} J$ General Practice. 2015;65(635):e387-400.

10. Sofat N, Hing CB. Pain sensitization in arthritis: cause or effect of chronic pain?. Int J Clin Rheumatol. 2015;10(3):143.

11. Grabovac I, Haider S, Berner C, Lamprecht T, Fenzl KH, Erlacher L, Quittan M, Dorner TE. Sleep quality in patients with rheumatoid arthritis and associations with pain, disability, disease duration, and activity. J clin medic. 2018;7(10):336.

12. Hinkle JL CK. Brunner \& Suddarth's Textbook of Medical-Surgical Nursing. 2017.

13. Ndosi M, Adebajo A. Patient education in rheumatoid arthritis: is the needs-based approach the way forward ;2015.

14. . Smith MC. Nursing theories and nursing practice. FA Davis; 2019 Oct 2.

15. Acob JR. Caring as Unending Expression of Nursing (CUEN): A theory of nursing. The Malaysian Journal of Nursing (MJN). 2018;10(2):52-7.

16. Mulford DL. Using the teach-back method to improve self-care behaviors. Hampton University; 2016.

17. Dinh TT, Bonner A, Clark R, Ramsbotham J, Hines S. The effectiveness of the teach-back method on adherence and self-management in health education for people with chronic disease: a systematic review. JBI Evidence Synthesis. 2016;14(1):210-47.

18. Potter PA, Perry AG, Stockert PA, Hall A, Peterson V. Clinical Companion for Fundamentals of Nursing-E-Book: Just the Facts. Elsevier Health Sciences; 2016 Feb 5.

19. Irwin MR, Olmstead R, Carrillo C, Sadeghi N, FitzGerald JD, Ranganath VK, Nicassio PM. Sleep loss exacerbates fatigue, depression, and pain in rheumatoid arthritis. Sleep. 2012;35(4):537-43.

20. Purabdollah M, Lakdizaji S, Rahmani A, Hajalilu M, Ansarin K. Relationship between sleep disorders, pain and quality of life in patients with rheumatoid arthritis. J Car Sci. 2015;4(3):233.

21. Sariyildiz MA, Batmaz I, Bozkurt M, Bez Y, Cetincakmak MG, Yazmalar L, Ucar D, Celepkolu T. Sleep quality in rheumatoid arthritis: relationship between the disease severity, depression, functional status and the quality of life. J Clin Medic Res. 2014;6(1):44.

22. Mustafa M, Bawazir Y, Merdad L, Wali S, Attar S, Fathaldin O, Bahlas S, Alhejaili F, Aljohaney A, Jan A, Jadu F. Frequency of sleep disorders in patients with rheumatoid arthritis. Open access rheumatology: Research and Reviews. 2019;11:163.

23. Austad C, Kvien TK, Olsen IC, Uhlig T. Sleep disturbance in patients with rheumatoid arthritis is related to fatigue, disease activity, and other patient-reported outcomes. Scandin J Rheumatol. 2017;46(2):95-103.

24. Rahnama N, Mazloum V. Effects of strengthening and aerobic exercises on pain severity and function in patients with knee rheumatoid arthritis. Int J Preven Medic. 2012;3(7):493-8.

25. Dalir Z, Reihani Z, Mazlom R, Vakilian F. Effect of training based on teach back method on selfcare in patients with heart failure. Journal of Mazandaran University of Medical Sciences. 2016;25(134):209-20. [Persian]

26. Taha NM, Ali ZH. Effect of reflexology on pain and quality of life in a patient with rheumatoid arthritis. Marsland Press. 2011;8:357-65. 